\title{
Efectos del fuego en la Virgen del Perdón, tabla novohispana del siglo XVI
}

Elsa M. Arroyo Lemus, Manuel E. Espinosa Pesqueira, Sandra Zetina Ocaña, Alfonso Torre Blanco, José Luis Ruvalcaba Sil, Eumelia Hernández Vázquez, Víctor Santos Vázquez y Alejandra Quintanar Isaías

Resumen: Se ha estudiado el efecto del fuego sobre la Virgen del Perdón de Simón Pereyns, pintura sobre tabla del siglo XVI que se incendió en 1967 en la Catedral de México. La interpretación fisicoquímica de las alteraciones producidas por el incremento en la temperatura procede de un experimento de reproducción de los estratos pictóricos desde el soporte que fueron sometidos a procesos de temperatura controlada. La presente investigación tiene su punto de partida en el conocimiento de la técnica de manufactura de la Virgen del Perdón, en la revisión de fuentes históricas y tratados de arte así como en el análisis científico comparativo entre los materiales originales y la reproducción experimental. El trabajo ha sido desarrollado desde una perspectiva interdisciplinaria con estudios de identificación biológica y de materiales inorgánicos a través de las técnicas: MO, DRX y MEB-EDX.

Palabras clave: Simón Pereyns, pintura sobre tabla, Nueva España, fuego, yeso, base de preparación, degradación

\begin{abstract}
The effect of fire on the Simón Pereyns's Virgen del Perdón was studied. This panel painting from sixteenth century was damaged in the 1967 fire at Mexico City Cathedral. The physicochemical interpretation of alterations due to the raise of temperature is based on experimental reproduction of the painting structure, starting from the support, which underwent controlled temperature increase. This research arise from the understanding of Virgen del Perdón manufacture technique, the revision of historical sources and art treatises, and the comparative scientific analysis between original materials and experimental reproductions. The study was developed from an interdisciplinary approach with biological identification of organic materials and characterization of inorganic materials through optical microscopy, XRD and SEM-EDS.
\end{abstract}

Keywords: Simón Pereyns, panel painting, New Spain, fire, gesso, gypsum, ground layers, degradation

Resumo: Tem sido motivo de estudo o efeito do fogo sobre a Virgen del Perdón de Simón Pereyns, pintura sobre tábua do século XVI que foi incendiada em 1967 na Catedral de México. A interpretação físico-química das alterações produzidas pelo incremento na temperatura, procede de um experimento de reprodução dos estractos pictóricos desde o soporte que foram sometidos a processos de temperatura controlada. A presente investigação têm o seu ponto de partida no conhecimento da têcnica de manufactura da Virgen del Perdón, na revisão de fontes históricas e tratados de arte assim como na análise científica comparativa entre os materiais originais e a reprodução experimental. $O$ trabalho tem sido desenvolvido desde uma perspectiva interdisciplinária com estudos de identificação biológica e de materiais inorgánicos através das têcnicas: MO, DRX e MEB-EDX.

Palavras-chave: Simón Pereyns, pintura sobre tábua, Nova Espanha, fogo, gesso, base de preparação, degradação.

\section{Introducción}

Dos años después de su llegada a la Nueva España, el pintor Simón Pereyns, flamenco de nacimiento, fue acusado de herejía por la Santa Inquisición. Fue encarcelado y torturado, y la sentencia emitida tras un largo juicio, obligó al artista a pintar con recursos propios un retablo para 
la antigua Catedral de México. El consenso historiográfico indica que la Virgen del Perdón fue la pintura que hizo Pereyns como resultado de esa penalización aunque no existe evidencia documental para saber la ubicación original del cuadro [figura 1].

Es sabido que la pintura permaneció en un altar de la Catedral y hasta 1725-37, se le recolocó en el renovado altar del Perdón ubicado a espaldas del coro (Arroyo, 2008: 9). El 18 de enero de 1967 hubo un incendio en la Catedral de México. Un corto circuito acabó con el Altar del Perdón y la sillería del coro. El primer cuerpo del altar resistió a las llamas pero la talla dorada y policromada que adornaba el retablo quedó dañada o fragmentada. Los daños producidos se intensificaron con el cambio de temperatura y la fuerza con la que los chorros de agua de los bomberos apagaron las llamas. El incendio se propagó durante tres horas, pero el humo y el calor que generó, no menguaron sino hasta 24 horas después. ${ }^{1}$
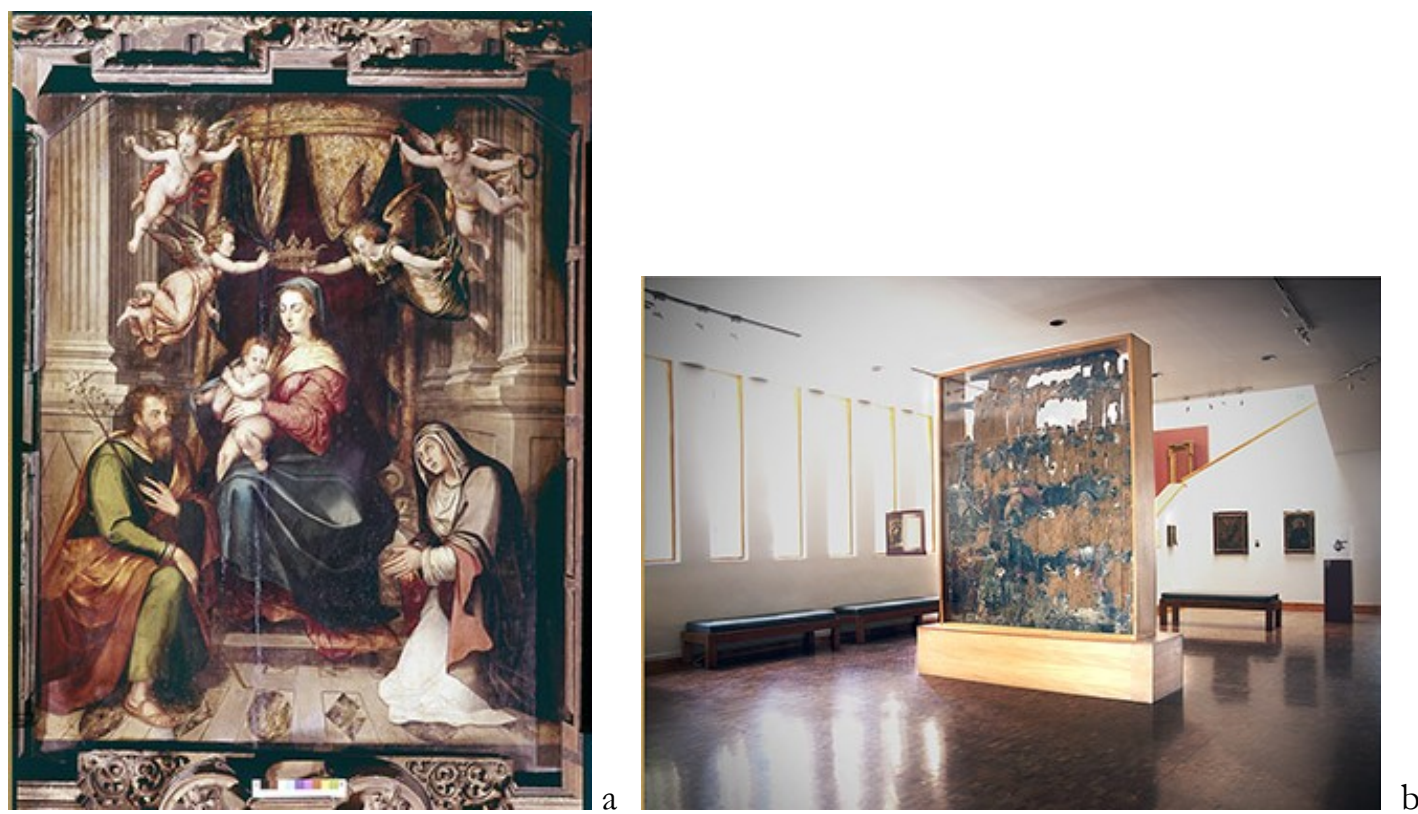

Figura 1. a) Simón Pereyns, La Virgen del perdón, óleo sobre tabla, Siglo XVI, 260 x 218 x $10 \mathrm{~cm}$. Exhibición museográfica en 2008. Foto: Félix Leonelli. Archivo fotográfico Manuel Toussaint, IIE-UNAM. b) Fotografía de la obra antes del incendio, ca.1965. Foto: Eumelia Hernández, 2008.

La Virgen del Perdón se quemó en un 80\% y el panel de madera quedó casi totalmente carbonizado. Los estratos pictóricos fueron parcialmente deslavados por la acción de los chorros de agua que desprendieron grandes áreas desde la base de preparación, dada la debilidad de las capas que a causa del fuego estaban abombadas, explotadas y craqueladas. Quedó expuesta la madera y el enfibrado que la cubre.

La obra fue sometida a tres tratamientos de estabilización estructural (1994, 1999 y 2008) en los cuales se consolidó la madera y fragmentos de capa pictórica con adhesivos tales como cola animal, acetato de polivinilo en emulsión (PVA), copolímero de etilo metacrilato (Paraloid B72) y resinas epóxicas expansivas. Ninguna de las intervenciones fue precedida de un estudio del deterioro y alteraciones de la obra. Este trabajo presenta la investigación realizada alrededor de la técnica de manufactura de la Virgen del Perdón, y la evaluación del deterioro provocado por el incendio a través de la experimentación con probetas. En ellas, se reprodujo la técnica de la pintura original y se sometieron a una curva de distribución de temperaturas para su caracterización con diferentes técnicas de análisis científico instrumental. 


\section{La técnica y materiales de la Virgen del Perdón}

La Virgen del perdón debió ser una de las primeras piezas que hizo Simón Pereyns en territorio novohispano, sus características técnicas difieren sustancialmente del corpus de pinturas del siglo XVI analizadas en el LDOA. (Amador 2008: 49-83) El estudio de la pieza se realizó in situ ${ }^{2}$ e incluyó una metodología de registro con diversos equipos y herramientas. ${ }^{3}$ Primeramente se efectuó la fotografía de alta resolución con luz visible, ultravioleta e infrarrojo, así como macrofotografías de detalle con iluminación frontal y rasante. También se hizo un estudio de reflectografía infrarroja y se llevó a cabo la caracterización de pigmentos mediante fluorescencia de rayos X (FRX) y Espectroscopia Raman. La última parte del proceso de estudio consistió en la toma de muestras de capa pictórica y madera, con la finalidad de procesarlas en el laboratorio por medio de microscopía óptica con luz polarizada e iluminación ultravioleta; finalmente se analizaron por medio de microscopía electrónica de barrido con microsonda de rayos X (MEB-EDX) y difracción de rayos $\mathrm{X}$ (DRX), para obtener datos sobre las capas pictóricas y materiales presentes desde la preparación de la tabla. Aunque la pintura estaba fragmentada y muy deteriorada, nos interesó saber qué tanta información se podía obtener a partir de un estudio riguroso de las islas de pintura y de la conformación del panel de madera.

El panel está constituido por siete tablones de madera de pino (Pinus sp.) de dimensiones irregulares colocados de manera vertical y unidos a hueso mediante cola animal. La estructura fue reforzada con siete travesaños horizontales de madera de cedro blanco (Cupressus sp.) de $10 \mathrm{~cm}$ de ancho, colocados con alrededor de 15 clavos de hierro en cada uno, que fueron clavados a intervalos regulares por el frente del panel [figura 2].

La identificación de maderas de la Virgen del Perdón se realizó por medio de un estudio anatómico e histoquímico en muestras tomadas de los tablones y travesaños. Se extrajeron muestras representativas de la madera de un tablón y de dos travesaños, de $1 \times 1 \times 0.5 \mathrm{~cm}$. Se hidrataron con una solución de alcohol-glicerol-agua y se incluyeron con una solución polimerizante para seccionar a $-20{ }^{\circ} \mathrm{C}$ en un crióstaro marca Leica. Se obtuvieron cortes transversales, tangenciales y radiales de cada muestra y se tiñeron con azul de toluidina para contrastar las membranas de las punteaduras y los campos de cruzamiento. ${ }^{4}$

La superficie de los tablones tiene un patrón de líneas diagonales incisas para facilitar la adherencia de la preparación. Esta obra tiene una característica muy singular, la unión entre tablones fue reforzada con un grueso entramado de tendones animales adheridos sobre toda la superficie frontal del panel con una pasta diluida de yeso (posiblemente anhidrita ya que es el material del que se constituye la capa gruesa en la Virgen del Perdón) abundante en cola animal. Al ser muy poca la cantidad de yeso entre las fibras animales no fue posible hacer DRX para confirmar su composición mineralógica. Existen referencias del siglo XVI en las se denomina 'ennervado' o 'encibado' al proceso de reforzar los tablones con tendones. Hasta ahora no hemos encontrado ningún análisis científico publicado dónde se presenten resultados de la caracterización de la naturaleza animal de las fibras. En esta obra se identificó la proteína constitutiva de las fibras animales. Una referencia puntual sobre el refuerzo con tendones como parte del proceso de construcción de retablos novohispanos, es el documento de 1580 para el desaparecido retablo de la Iglesia de la Purísima Concepción, Ciudad de México. En esta fuente se le denomina 'encibado' al proceso de refuerzo de los tablones. ${ }^{5}$ Es interesante notar que el uso del 'ennervado' así como los múltiples refuerzos (clavos, travesaños de cedro blanco, etc.) en la Virgen del Perdón, parecen buscar la estabilidad de la madera de pino, puesto que en las referencias documentales el 'ennervado' se aplica en la parte posterior del tablero, entre las juntas y no en toda la superficie a pintar, parecería una adecuación ante materiales no probados y frente a la necesidad de resolver un problema estructural de grandes dimensiones. 

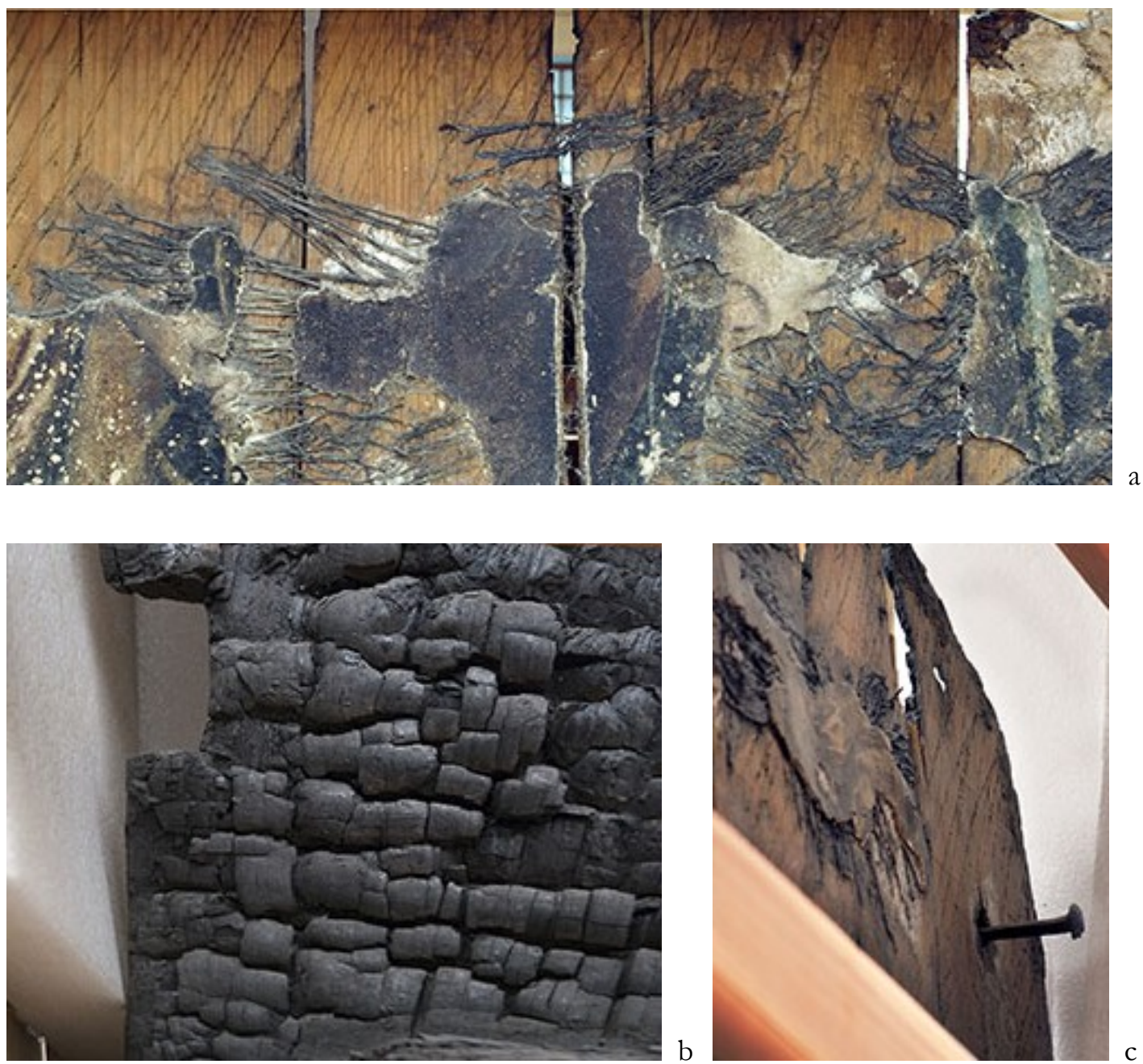

Figura 2. Detalles comparativos del panel. a) Madera con incisiones y fragmentos de pintura con enfibrado b) Madera carbonizada, reverso c) Clavos de hierro. Fotos: Eumelia Hernández, 2008

Un examen preliminar del enfibrado, realizado en el microscopio óptico y en microfotografías obtenidas en MEB, mostró que no se trataba de fibras vegetales, sino de fibras de origen animal. Para llevar a cabo la identificación del material fibroso se realizó una determinación del contenido de hidroxiprolina, el aminoácido característico de las fibras de colágeno. Se tomaron muestras de las fibras que estuvieran libres del yeso procedente de la base de preparación; se lavaron en agua destilada y se hidrolizaron con $\mathrm{HCl} 6 \mathrm{~N}$ en ampolletas selladas, a $115^{\circ} \mathrm{C}$, durante 18 horas. Después de la hidrólisis las ampolletas se abrieron y se evaporó la disolución hasta sequedad. El residuo seco se disolvió en agua destilada y se utilizó para la medición de hidroxiprolina mediante el método descrito por Woessner. (Woessner 1961: 440-447) Los resultados mostraron que las fibras tienen un alto contenido de hidroxiprolina, típico del colágeno, lo que aunado a su aspecto macro y microscópico sugiere que se trata de fibras obtenidas de tendones. La enorme fuerza tensil de las fibras de colágeno era conocida desde la antigüedad, esta es la razón de su uso artesanal.

La construcción de la base de preparación de la Virgen del Perdón fue ejecutada siguiendo cada uno de los pasos que sugiere Pacheco en El Arte de la pintura publicado en 1649 (Pacheco 2001: 480481), ${ }^{6}$ aunque desde el tratado de 1437 de Cennino Cennini (Cennini 1947: CXVI-CXVII), se indica que la preparación de las tablas debe poseer dos estratos aplicados diferenciadamente, el primero de gesso grosso y el segundo de gesso sottile, ${ }^{7}$ práctica confirmada en la tradición pictórica italiana desde la época carolingia. (Martin 1992: 82) 
La primera capa de preparación de la Virgen del Perdón consiste en una sola aplicación de yeso grueso (gesso grosso) que tiene un espesor de 600 micras $(\mu \mathrm{m})$ en promedio. Por medio de DRX se identificó que la base de preparación gruesa está compuesta por una pasta aglutinada con cola animal que se compone de sulfato de calcio anhidro (anhidrita) en una proporción de 93\%, mezclada con cuarzo en $1.3 \%$ y basanita en $5.4 \%$ con escasas partículas de óxido de hierro y carbón vegetal. Sobre ésta capa se aplicó el yeso mate (gesso sottile), es un estrato homogéneo y de color blanco, su espesor es de aproximadamente $254 \mu \mathrm{m}$. El estudio de la composición y fase cristalina de esta capa fina determinó que se trata de una mezcla de sulfato de calcio dihidratado $\left(\mathrm{Ca}\left(\mathrm{SO}_{4}\right) \cdot 2 \mathrm{H}_{2} \mathrm{O}\right)$ con cuarzo, aglutinada con cola animal. En las microfotografías obtenidas por MEB a través de un detector de electrones retrodispersados, se observó la cristalización, compactación y orientación del yeso, así como la interfase de cada capa aplicada por el artista [figura 3].
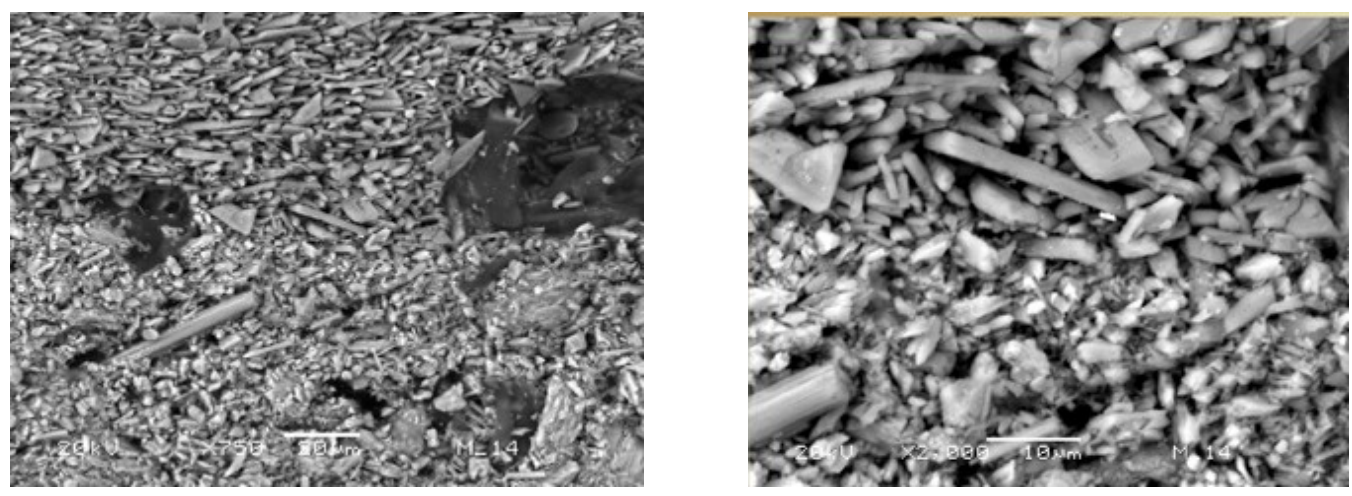

Figura 3. Microfotografías de una sección transversal de la base de preparación de la Virgen del Perdón donde se aprecia la interfase de las capas de yeso grueso y mate. MEB 740 x y 2000x

Se ha identificado como parte de la preparación, una capa aislante o de sellado color amarillo intenso que presenta una fluorescencia característica de color naranja brillante bajo iluminación ultravioleta, como se aprecia en la microfotografía. Este aglutinante es un aceite que fue evidenciado mediante tinciones con negro de sudán y rojo oleoso, cuya función es conferir a la capa de yeso fino una superficie compatible con el medio, que aglutina los pigmentos en la capa pictórica y evita la absorción del aceite de la pintura. Dada su naturaleza orgánica, fue afectado por el calor que generó el incendio. Al observar las secciones transversales de la pintura bajo el microscopio óptico, se ve el reblandecimiento del material aglutinante y el burbujeo que causó el desprendimiento parcial de los estratos pictóricos. Nótese en las microfotografías que la zona de mayor desprendimiento de las capas pictóricas se localiza en la imprimatura, aunque desde el sellado comenzó la separación y burbujeo [figura 4].

La Virgen del Perdón fue pintada sobre una imprimación o capa de fondo de color amarillo claro cuyo espesor oscila entre 35 y $80 \mu \mathrm{m}$. Se trata de una mezcla de aglutinante oleoso con dos pigmentos inorgánicos: blanco de plomo y un pigmento de cualidades secativas compuesto de plomo y que se conoce como amarillo de plomo o litargirio, con abundancia del primero, a los que se agregó calcita empleada como carga añadida de calidad inferior para abaratar el pigmento. Esta capa es homogénea en toda la superficie del cuadro y por su contenido de aceite, también fue afectada por el calor durante el incendio. Aquí se generaron burbujas de la capa pictórica, siendo las zonas intermedia y superior donde se identificaron las explosiones más severas. 


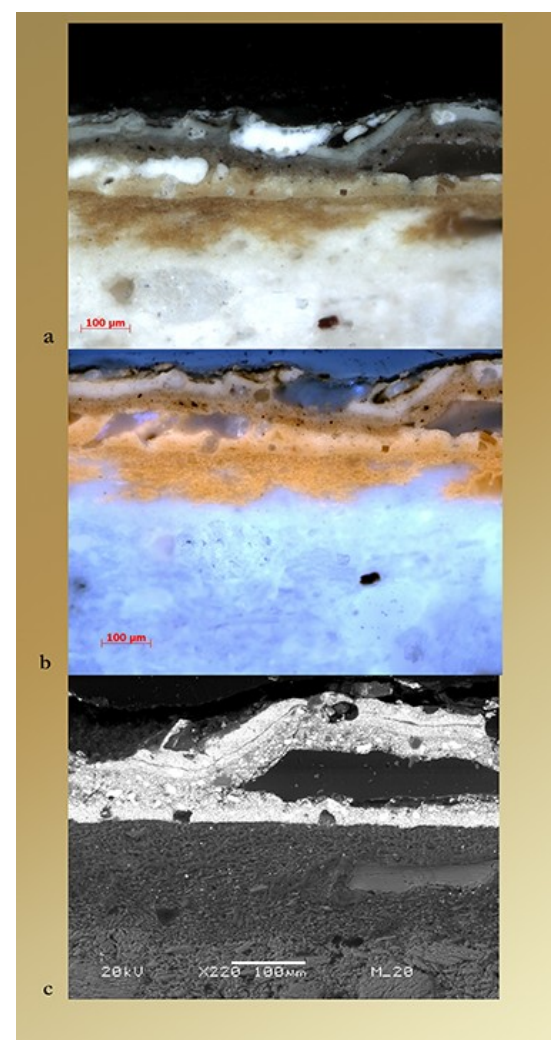

Figura 4. Sellado de la base de preparación y fluorescencia característica del aceite en la imprimatura de la Virgen del Perdón donde se aprecia la separación de los estratos por efectos del calor. a) Muestra de la manga de Santa Ana, sección transversal, microscopia óptica campo oscuro, 10x b) Sección transversal en microscopia óptica ultravioleta, 10x c) Imagen MEB, 220x

La interpretación de la técnica pictórica en los fragmentos conservados es difícil ya que la obra perdió las capas superficiales a causa del fuego y el agua que se usó para apagar el incendio. Por ello, hemos utilizado en la interpretación de la aplicación del color tanto los datos que proporcionan las muestras estudiadas en laboratorio, como las macrofotografías tomadas directamente de la superficie y detalles de dos placas fotográficas que fueron captadas dos años antes del incendio. ${ }^{8}$

El sistema de ejecución del colorido9 en la Virgen del Perdón comenzó con la construcción de las figuras humanas: rostros y encarnaciones, partiendo de una base conformada de mezclas de pintura espesa donde el blanco de plomo funciona como el pigmento más importante. (Arroyo 2008: 48) Sobre este color se fueron modelando las áreas de luz y sombra, con adición de rojo, azul y tierras. En las sombras se observó veladura entonada con pigmentos oscuros: tierra color pardo y tierra roja, ambas con alto contenido de óxidos de hierro, mezcladas con aglutinante en mayor proporción. Para ejemplificar este sistema de aplicación del color se ha elegido la figura de Jesús donde el tono base fue creado a partir de una mezcla de blanco de plomo con un poco de rojo óxido de hierro, tierra de sombra tostada y un poco de negro de carbón. En las luces aumentó la cantidad de blanco de plomo y fue mezclado con bermellón, laca orgánica roja, azul esmalte y tierra de sombra tostada. La transición del color entre luces y sombras fue realizada mediante un difuminado muy suave donde es difícil percibir la huella del pincel. Para los detalles anatómicos y el trazo de cejas, ojos y líneas de contorno, usó un pincel muy fino, con una ejecución dibujística de líneas continuas. 

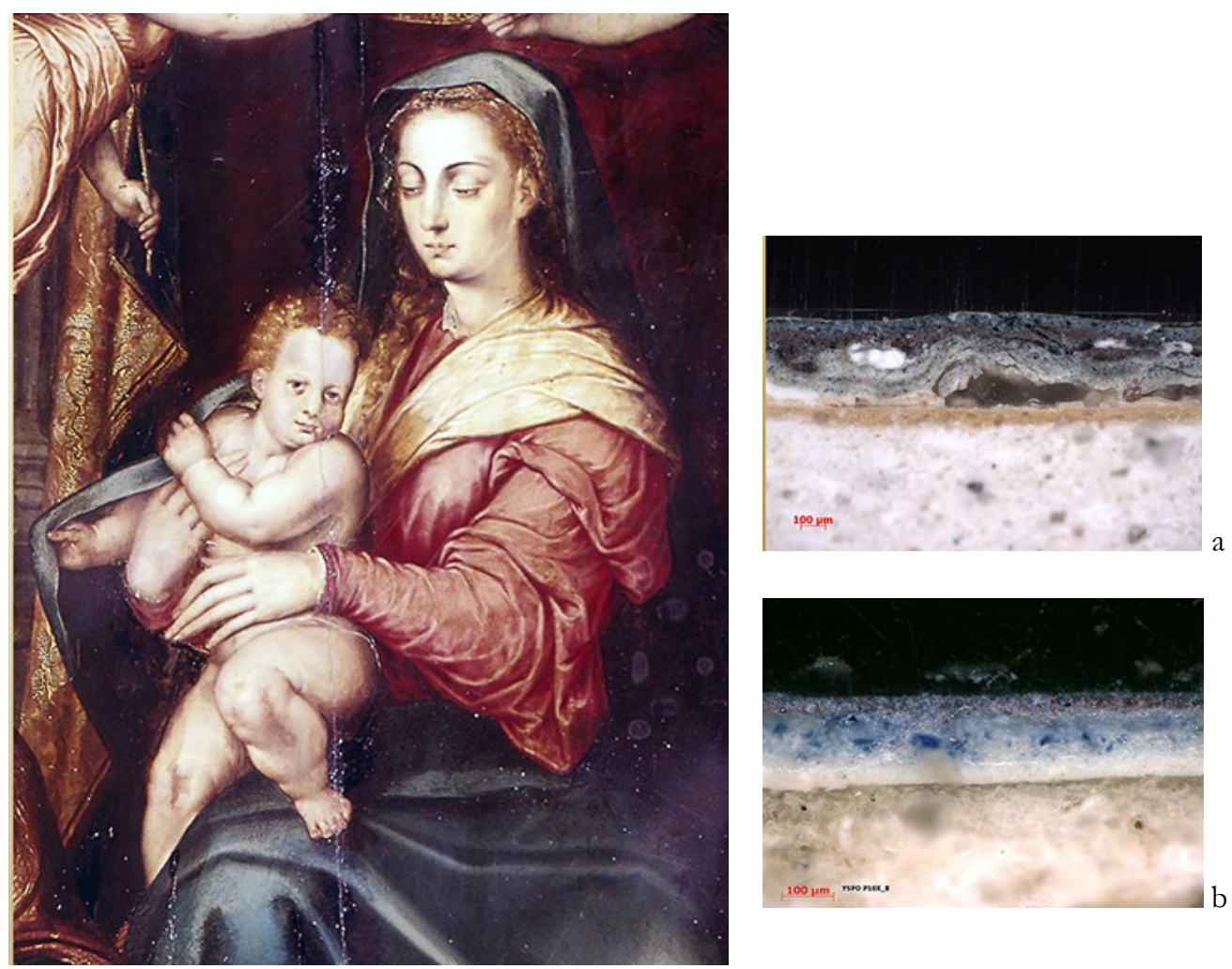

Figura 5. Detalle de la Virgen María. a) En la sección transversal de la Virgen del perdón se observa la compleja construcción del manto azul con superposiciones de tres tonos: azul, rojo y violeta. b) La reproducción de la obra en la probeta de la serie No. 3 iguala este efecto cromático. Microscopia óptica con polarización, 10x

Uno de los rasgos más notables en el proceso de aplicación del color de la Virgen del Perdón se observa en la solución de los paños, donde destaca la variedad de efectos cromáticos empleados por el artista. En las vestimentas de los ángeles, el efecto buscado era el de la seda tornasolada y se consiguió a partir de un tono de base enriquecido con veladuras superpuestas aplicadas cuando la pintura todavía estaba fresca. En contraste, la vestimenta de María presenta un cuidado extremo en su representación. El artista buscó diferenciar el vestido delicado de seda transparente respecto al pesado manto de color azul intenso cuyo brillo metálico hace pensar en una tela de terciopelo. Llama la atención la multiplicidad de capas y la mezcla de pigmentos con la que se plasmaron los tonos rojos y rosados del vestido. A partir del estudio de una muestra de la manga del brazo izquierdo pudimos caracterizar el color rosa. Se trata de una capa delgada de aproximadamente 15 $\mu \mathrm{m}$ de espesor que contiene una mezcla de blanco de plomo, bermellón, partículas de laca orgánica roja y un poco de tierra de sombra tostada y azul esmalte, éstos últimos sirvieron para dar una tonalidad violácea al color. Cuando la capa hubo secado, el artista procedió a pintar luces y sombras. En las sombras, el medio se enriqueció con mayor cantidad de aceite y una laca orgánica roja. Las luces son pinceladas de blanco puro, aplicadas a modo de empaste y cuyo espesor en el corte transversal es de $32 \mu \mathrm{m}$.

El manto azul de la Virgen ejemplifica la complejidad de superposiciones que utilizó el pintor. En la representación de esta tela azul con sombras violáceas, se aprecia la confianza del pintor en el poder del óleo como un medio que permite la transposición de capas traslúcidas. En principio aplicó una capa gruesa de color azul claro que tenía la función de base, es un estrato de $126 \mu \mathrm{m}$ aproximadamente donde el color es conferido por el azul esmalte mezclado con blanco de plomo. Sobre éste estrato una vez seco, se aplicó una capa de color rosa oscuro producto de la mezcla de pequeñas partículas de rojo óxido de hierro, blanco de plomo, azurita y partículas de laca orgánica 
roja, el espesor de la capa completa es entre 52 y $112 \mu \mathrm{m}$. Al final, en las zonas de azul oscuro, se usó una mezcla de azurita de gran tamaño de partícula, laca orgánica roja, azul esmalte y un poco de blanco de plomo [figura 5]. El colorido del manto es tan interesante, que fue usado como modelo para la fabricación de la serie No. 3 correspondiente a las probetas de reproducción de técnica.

\section{Metodología y experimentación}

A partir de los materiales y técnica identificados en la Virgen del Perdón se realizaron probetas que fueron sometidas a diversas pruebas para evaluar los efectos de la temperatura controlada sobre los materiales de estudio. Se hizo la reproducción experimental de la pintura en tres series, la serie $\mathrm{N}^{\mathrm{o}} 1$ tuvo la finalidad de evaluar los efectos del calor sobre el yeso mate a distintos intervalos de temperatura, la serie $\mathrm{N}^{\circ} 2$ estudió el comportamiento del yeso sin ningún tratamiento de lavado (como el yeso grueso), la serie $\mathrm{N}^{\circ} 3$ reproduce todos los estratos de la obra, siguiendo como modelo el manto azul de la Virgen. En total se elaboraron nueve muestras, seis se expusieron a calor controlado en un horno de convección natural. ${ }^{10} \mathrm{El}$ procedimiento se hizo precalentando el horno a la temperatura deseada, se introdujo la muestra y se dejó por espacio de dos horas. En cada una de las series se reservó una probeta sin calentamiento como referencia. Cabe señalar que las probetas no fueron sometidas a envejecimiento inducido, únicamente a tratamiento térmico.

En todas las probetas se utilizó madera de caoba como soporte, sellada con cola de conejo. En la serie $\mathrm{N}^{\circ} 1$ se aplicó yeso mate y en la $\mathrm{N}^{\circ} 2$ yeso grueso como se explica más adelante. La serie $\mathrm{N}^{\circ} 3$ tiene una preparación más compleja, primero se ennervó la madera con fibras de tendones de ternera adheridos mediante una pasta de yeso y cola, muy diluida. Los tendones se sumergieron en agua de cal durante una semana con la finalidad de flexibilizarlos y posteriormente fueron separados en fibras delgadas. La base de preparación, compuesta de yeso aglutinado con cola se aplicó en dos capas, la primera de yeso grueso y la segunda de yeso mate [tabla 1] como lo indican los tratados de Cennini y Pacheco y según se ha observado en el estudio de las muestras originales. El yeso grueso empleado fue un material comercial de la marca mexicana Cosmopolita ${ }^{\circledR}$ cuya identificación mediante DRX fue $84.9 \%$ de bassanita, $14 \%$ de anhidrita y $1.10 \%$ de yeso $\left(\mathrm{Ca}\left(\mathrm{SO}_{4}\right) \cdot 2 \mathrm{H}_{2} \mathrm{O}\right)$; el yeso mate empleado se compone de $100 \%$ de yeso en la fase cristalina que corresponde a la fórmula: $\mathrm{Ca}(\mathrm{SO} 4) \cdot 2 \mathrm{H} 2 \mathrm{O} .{ }^{11} \mathrm{El}$ yeso Cosmopolita en polvo se mezcló directamente con la cola preparada $(75$ $\mathrm{g}$ de cola de conejo en perla disuelta en 1 litro de agua) para preparar la pasta de yeso grueso. Respecto al yeso mate, se siguió al pie de la letra la indicación de Cennini, el yeso Cosmopolita se hidrató durante 3 meses sumergido en agua purificada, y se removía frecuentemente. Se obtuvieron "panes" mediante un proceso de decantación y filtrado del yeso hidratado con tela. Los panes se dejaron secar al aire libre tras lo cual, se rehidrataron y se volvieron a filtrar. Esta pasta final de yeso re-hidratado se mezcló con la cola de conejo para formar el yeso mate. La consistencia de esta pasta es espesa, con una textura de grano diminuto y muy homogéneo, que al secar tiene una superficie tersa, muy brillante, sin aglomeraciones, lista para pulirse con gran facilidad.

Para imprimar las probetas de la serie $\mathrm{N}^{0} 3$ se usó blanco de plomo y amarillo de plomo estaño aglutinados con aceite de linaza cocido. ${ }^{12}$ Se aplicaron tres capas pictóricas: primero una capa de blanco de plomo con azul esmalte, después un estrato de blanco de plomo, rojo de óxido de hierro, laca roja de cochinilla y azurita, la última capa contiene blanco de plomo, con abundante azurita, laca roja y esmalte. 


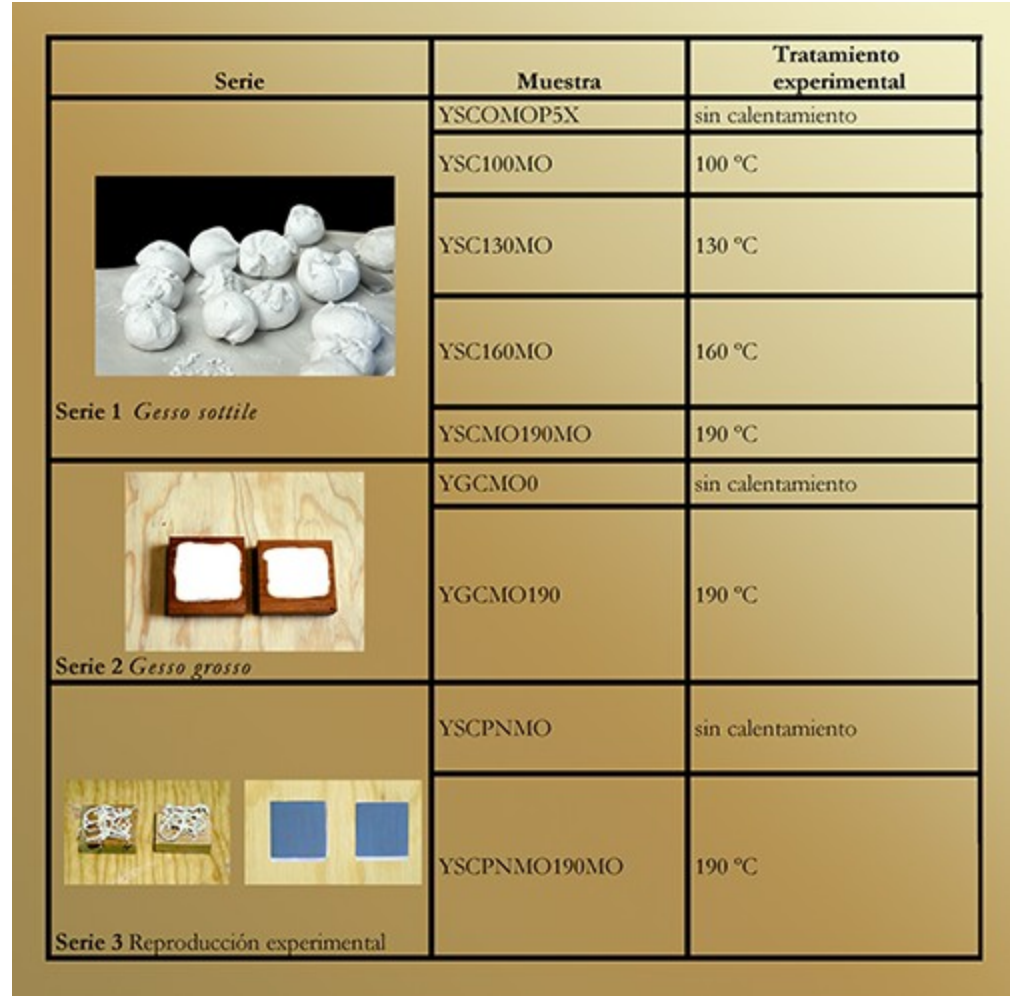

Tabla 1. Probetas preparadas para experimentación. Series No. 1,2 y 3.

Los métodos analíticos de caracterización material empleados fueron: microscopía óptica, MEBEDX y DRX con el objetivo de buscar cambios morfológicos, topológicos, alteraciones en la estructura pictórica y transiciones de fase cristalina. Se prepararon secciones transversales ${ }^{13}$ de todas las probetas y se estudiaron en un MEB de última generación JEOL JSM 6610-LV con una resolución puntual de 3 nanómetros en modalidad de bajo vacío utilizando un detector de electrones retrodispersados para apreciar la diferencia topológica y en composición química de los elementos constitutivos. Este MEB tiene acoplado un microanálisis EDX acoplada, marca Oxford (INCA X-act), libre de nitrógeno líquido. Asimismo se estudió en el MEB Philips XL-30 a 20 kV la superficie y una vista transversal de probetas enteras, preparadas depositando con una capa delgada de oro por el método de pulverización catódica para favorecer la conductividad de la muestra. DRX se realizó en un equipo SIEMMENS D 5000, las muestras fueron pulverizadas y se utilizó la misma cantidad de las probetas en polvo para realizar el análisis semicuantitativo de las fases presentes en cada una de las muestras. Las condiciones experimentales fueron $40 \mathrm{kV}$ y $30 \mathrm{~mA}$ con un tamaño de paso de $0.03^{\circ} 2 \theta$ y un tiempo de paso de $1 \mathrm{~s}$. La identificación de fase cristalina se hizo utilizando la base JCPDS-ICDD vs. 2.0704 .

\section{Evaluación de los efectos del fuego sobre los materiales de la Virgen del Perdón}

La madera en tanto material combustible se descompone químicamente a temperaturas superiores a $120^{\circ} \mathrm{C}$, originando carbón y gases inflamables. La resina presente en la madera comienza a fundirse a partir de los $100^{\circ} \mathrm{C}$ y es posible que la temperatura en el incendio haya alcanzado alrededor de $230^{\circ} \mathrm{C}$, que es el rango que alcanza un incendio en bosques de pino reproducido experimentalmente en laboratorio. ${ }^{14}$ En la Virgen del Perdón encontramos señales de ebullición de la resina en los nudos. 
Otro efecto del calor fue la presencia de áreas de separación entre el panel y los estratos preparatorios que se fracturaron en grandes segmentos. Durante la experimentación para identificar la naturaleza de las fibras de la obra observamos que al realizar el lavado con agua destilada, se hincharon y formaron un gel blando, flexible y translúcido; este comportamiento, que no es el típico de las fibras de colágena nativa, indica que sufrieron un proceso de desnaturalización debido al calor al que estuvieron expuestas. Los haces macroscópicos de fibras de colágeno sufren una abrupta disminución de su longitud cuando se someten a calentamiento, esta contracción es una manifestación macroscópica de la transición colágeno-gelatina o desnaturalización (Von Hippel 1967: 253-338; Ramachandran 1967: 103-183). Es muy probable que la contracción de los tendones que se identificaron como parte de la preparación del panel haya contribuido a la formación de burbujas entre la madera y los estratos preparatorios. Por esa separación, el agua a presión de los bomberos arrastró las zonas más afectadas por el calor, que eran las que se encontraban en las regiones más expuestas, es decir, dónde no hay travesaños. La separación entre tendones y madera también fue registrada en las probetas que fueron sometidas a calentamiento en condiciones controladas (ver tabla 3).

Al comparar los resultados del calor en probeta respecto a la obra original, se observó que la estabilidad material que había alcanzado la película pictórica de aceite por un paulatino proceso de envejecimiento y reticulación produjo resistencia al calor, no así la probeta donde este era muy superficial. El aglutinante se contrajo y se quemó, lo que se tradujo en un oscurecimiento del material. Las capas ricas en aglutinante y las veladuras fueron las más alteradas en su calidad tonal y algunas desaparecieron por completo, transformándose en una capa amorfa de color pardo oscuro. La capa que experimentó el mayor efecto de burbujeo fue la imprimatura o imprimación produciéndose ampollas que se expandieron hasta la superficie de la pintura -ver figura 4-.

El papel de la base de preparación para la conservación de la pintura fue fundamental. Las capas de yeso funcionaron como una excelente barrera de aislamiento térmico; de hecho, la madera más superficial se conservó por estar en contacto con la base de preparación que no permitió que entrara en combustión. Sorprendentemente, el milímetro de madera estable que quedó en superficie es el que sostiene el carbón y la estructura de siete travesaños. Esta condición en los tablones de madera que forman el panel permitió que la estructura celular diagnóstica se conservara, lo que hizo posible la determinación de las especies de madera: Pinus sp. y Cupressus sp. En este trabajo pensamos que la especie de pino puede ser ayacahuite, ya que presenta caracteres microscópicos diagnósticos como son: pocos canales verticales y de radio y campos de cruzamiento de tipo fenestroide, que sugieren esa determinación. Este tipo de pino ha sido muy apreciado en México por sus características de trabajabilidad, resistencia, baja densidad de nudos y poca resina. Es importante resaltar que la selección de este tipo de madera para la tabla del perdón indica el conocimiento del artífice sobre la calidad de esta especie.

Para evaluar el efecto del fuego en la estratigrafía de la base de preparación, se realizó un estudio de MEB de las probetas de yeso mate y yeso grueso con el propósito de detectar los cambios morfológicos y topológicos provocados por la temperatura en los minerales y el aglutinante, en vista superior y transversal [tabla 2]. Las imágenes (a) y (b) muestran el yeso mate sin tratamiento, se aprecia la morfología de tipo tabular y prismática, y se observó que la cola animal forma velos que rodean los cristales de yeso dihidratado. A $100^{\circ} \mathrm{C}$ se encontró un cambio morfológico significativo, los cristales tabulares se encuentran fraccionados y compactados por la transición de fase de una estructura monoclínica a una ortorrómbica (c) y (d) con agregados de partículas menores a $2.5 \mu \mathrm{m}$. El tratamiento a $130^{\circ} \mathrm{C}$ provocó fracturas en los cristales tabulares, imágenes (e) y (f), así como degradación del aglutinante, que se observa como delgados hilos en la superficie de los cristales. A mayor temperatura $\left(160^{\circ} \mathrm{C}\right)$ encontramos grandes fracturas en los cristales tabulares de bassanita que comienzan a formar pequeños gránulos (h). En vista transversal (g) se observa una mayor compactación de la capa de yeso mate. A $190^{\circ}$ ocurre el mismo comportamiento (i), gránulos individuales rodeados por hilos de colágena muy degradada se aprecian en la vista transversal (j). Las imágenes de microscopía electrónica revelan el proceso de deshidratación paulatina del yeso 
mate y la transición de fase cristalina, cuya consecuencia fue la fractura de los cristales, hasta separarse en otros de tamaño menor a 5 micrómetros.

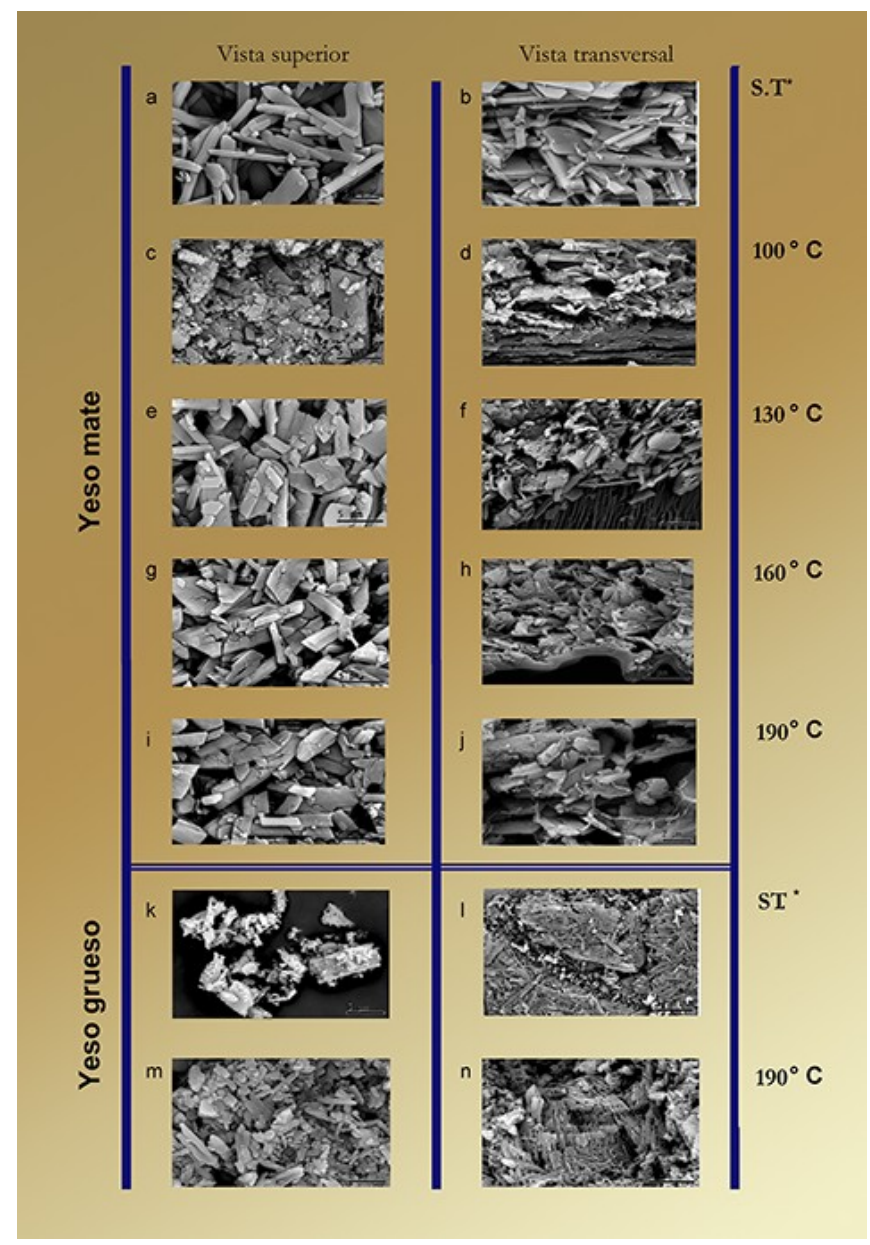

Tabla 2. Imágenes MEB de los cambios morfológicos y topológicos provocados por la temperatura en el yeso y el aglutinante. Vista superior y transversal.

El yeso grueso, (k) y (l), por su procesamiento industrial, muestra una morfología de cristales prismáticos altamente compactados. Tras el tratamiento a $190^{\circ} \mathrm{C}$ se detectaron poros al centro de los cristales prismáticos, lo que no se presentó en el yeso mate.

Al comparar las imágenes MEB del yeso mate y el yeso grueso que no fueron sometidos a tratamiento térmico, podemos afirmar que los cambios ocurridos al hidratar el yeso grueso suspendido en exceso de agua durante periodos prolongados de tiempo -como lo recomiendan los tratadistas consultados Cennini y Pacheco-, se traducen en cristales con tamaño y morfología homogénea de ángulos rectos, así como en partículas tabulares y prismáticas.

Por otro lado, la interpretación del análisis mediante microscopia óptica de los cortes transversales de las probetas preparadas demostró la contracción de la base de preparación, que pierde porosidad y se fractura en un patrón de líneas paralelas al soporte de madera. A partir de $100^{\circ} \mathrm{C}$ comienza el fenómeno de separación y a $160^{\circ} \mathrm{C}$ se forma un estrato heterogéneo con zonas cavernosas y otras de alta compactación. Es posible que este comportamiento mecánico se relacione con la degradación y contracción de la cola animal que envuelve al yeso, debido a los efectos del calor 
[tabla 3]. En MEB se confirmó este efecto en la morfología microscópica del yeso, a través de un análisis comparativo de las vistas transversales entre la muestra que no se sometió a calor y el resto de la serie. También se observó la fuerte degradación del aglutinante (ver tabla 2).

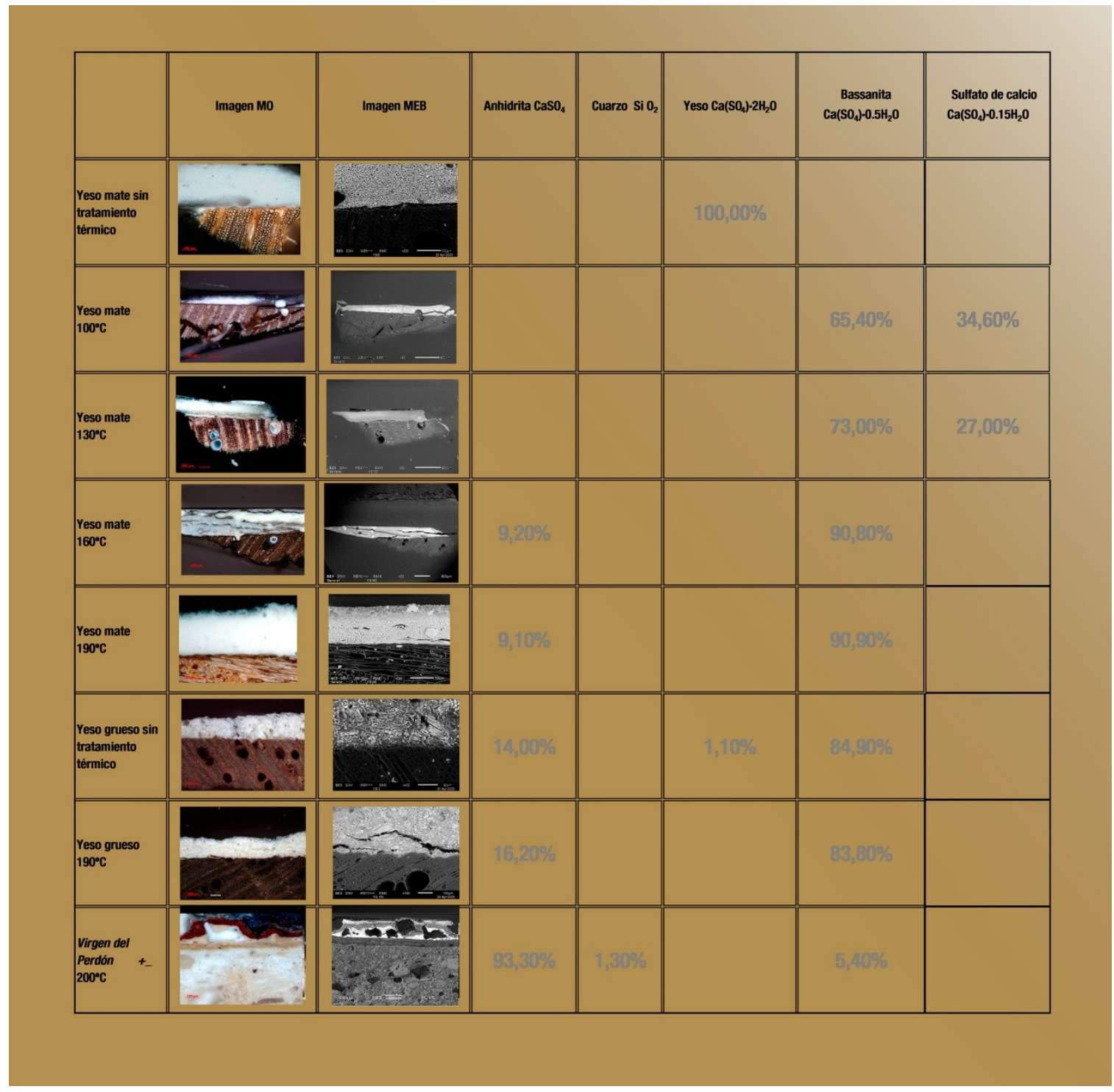

Tabla 3. Identificación mediante DRX de fases cristalinas y porcentaje en peso de los minerales presentes en las probetas de yeso mate y yeso grueso tratados a distintas temperaturas $\left(100-190^{\circ} \mathrm{C}\right)$ y en la preparación de la Virgen del Perdón.

El análisis de las probetas preparadas mediante DRX, confirmó la transición de fase cristalina del yeso mate a consecuencia del tratamiento térmico a $100{ }^{\circ} \mathrm{C}$. El yeso $\left(\mathrm{Ca}\left(\mathrm{SO}_{4}\right) \cdot 2 \mathrm{H}_{2} \mathrm{O}\right)$ se transformó en basanita $\left(\mathrm{Ca}\left(\mathrm{SO}_{4}\right) \cdot 0.5 \mathrm{H}_{2} \mathrm{O}\right)$. El análisis semicuantitativo del porcentaje en peso de estas fases reportó $65.4 \%$ de basanita y $34.6 \%$ de la fase cristalina de sulfato de calcio $\left(\mathrm{Ca}\left(\mathrm{SO}_{4}\right)\right.$. $\left.0.15 \mathrm{H}_{2} \mathrm{O}\right)$. A $130{ }^{\circ} \mathrm{C}$ en el yeso mate aumentó el porcentaje de basanita a $73 \%$ y descendió la fase cristalina de sulfato de calcio $\left(\mathrm{Ca}\left(\mathrm{SO}_{4}\right) \cdot 0.15 \mathrm{H}_{2} \mathrm{O}\right)$ a $27 \%$ en peso; esto demuestra la paulatina pérdida de moléculas de agua presentes en la fase original de yeso. Cuando el tratamiento se elevó a $160^{\circ} \mathrm{C}$ y $190{ }^{\circ} \mathrm{C}$, predominaron las fases de basanita y de anhidrita. Lo que implica que la fase de sulfato de calcio $\left(\mathrm{Ca}\left(\mathrm{SO}_{4}\right) \cdot\left(0.15 \mathrm{H}_{2} \mathrm{O}\right)\right.$ es metaestable, es decir, es susceptible a cambios provocados por variaciones de temperatura entre 100 y $130{ }^{\circ} \mathrm{C}$ [tabla 3]. ${ }^{15}$ 
En el caso del yeso grueso el tratamiento térmico tuvo pocas consecuencias, a $190^{\circ} \mathrm{C}$ únicamente se observó la eliminación de la fase dihidratada de yeso y un ligero incremento en el porcentaje en peso de la anhidrita.

En comparación, en el análisis de DRX en la muestra de la Virgen del Perdón, fueron identificadas las fases de anhidrita en una proporción de $93 \%$, cuarzo en $1.3 \%$ y basanita en $5.4 \%$. Estos resultados plantean dos hipótesis en relación con el material constitutivo de la obra original: si el contenido de anhidrita deriva del uso de yeso grueso por parte del artista cuando creó la pintura o bien, si es resultado de una alteración debida al aumento de la temperatura tras el incendio. No contamos con muestras de la Virgen del Perdón previas al siniestro, pero se infiere que en su preparación original el yeso grueso se conformaba de anhidrita principalmente. En este sentido, estudios publicados sobre tablas italianas y españolas del siglo XVI indican que era frecuente encontrar anhidrita formando parte del yeso grueso, mientras que el yeso mate está compuesto por yeso $\mathrm{CaSO}_{4} \cdot 2 \mathrm{H}_{2} \mathrm{O}$. En 1954 Gettens identificó anhidrita y yeso en gesso grosso y sottile, a través de DRX por el método de polvo cámara de Debye-Schererr-(Gettens 1954: 174-189). Otros estudios de pinturas italianas del s.XVI han mostrado la presencia de anhidrita hasta en un 100\% en el gesso grosso (Martin 1992: 88-89). En pinturas españolas, se han realizado estudios para reproducir experimentalmente e identificar la preparación de las tablas a partir de materias primas localizadas en bancos españoles: lapis specularis y yeso alabastroso. Los resultados comparativos con obras españolas del siglo XVI y XVII, han mostrado que era común la aplicación de los dos estratos de yeso grueso y mate. (Santos 2008: 178179). Por los resultados experimentales que aquí se reportan, es posible suponer que a partir de los $100{ }^{\circ} \mathrm{C}$ el yeso de la Virgen del Perdón sufrió deshidratación y una fragmentación de los cristales laminares. El porcentaje de bassanita en la mezcla puede ser consecuencia del cambio de fase cristalina del yeso.

Respecto a la pintura novohispana, se han publicado estudios de tablas atribuidas al pincel de Andrés de Concha y en ellos se reportó el uso de anhidrita como material constitutivo de la preparación. Se ha visto en las obras de Concha la presencia de un solo estrato de yeso grueso, carente de la capa fina. (Amador 2008: 64) Al contrastar esto con los resultados del análisis de materiales de la Virgen del Perdón donde vemos una estratigrafía bien definida con la presencia de yeso grueso y mate, se plantea la posibilidad de que este tipo de reconocimiento de patrones a través de los análisis fisicoquímicos, pueda contribuir al conocimiento diferenciado de los proyectos retablísticos novohispanos. Cabe hacer mención que Andrés de Concha y Simón Pereyns trabajaron en sociedad en varios retablos durante la década de $1580 .{ }^{16}$

Tras el análisis científico de los materiales de la Virgen del Perdón fue posible determinar la alteración del azul esmalte. En los cortes transversales vemos que en el interior de las capas que contienen este pigmento hay partículas de una tonalidad grisácea traslúcida, en ellas, el contenido elemental que da el color azul se ha modificado, como se demuestra con los análisis mediante MEB- EDX. En esas partículas ha disminuido el contenido de potasio, lo cual indica una reacción con los ácidos grasos del aceite en que están suspendidos y la formación de un jabón de potasio. Este fenómeno de degradación del azul esmalte ha sido estudiado por Marika Spring para pinturas de los siglos XVI al XVIII. ${ }^{17}$ (Spring, 2005: 56-70). En el caso de la Virgen del perdón la temperatura aceleró la reacción del azul esmalte con el aceite provocando su decoloración. Se confirmó este fenómeno en la probeta de la serie No. 3 sometida a $190^{\circ} \mathrm{C}$ [figura 6]. 


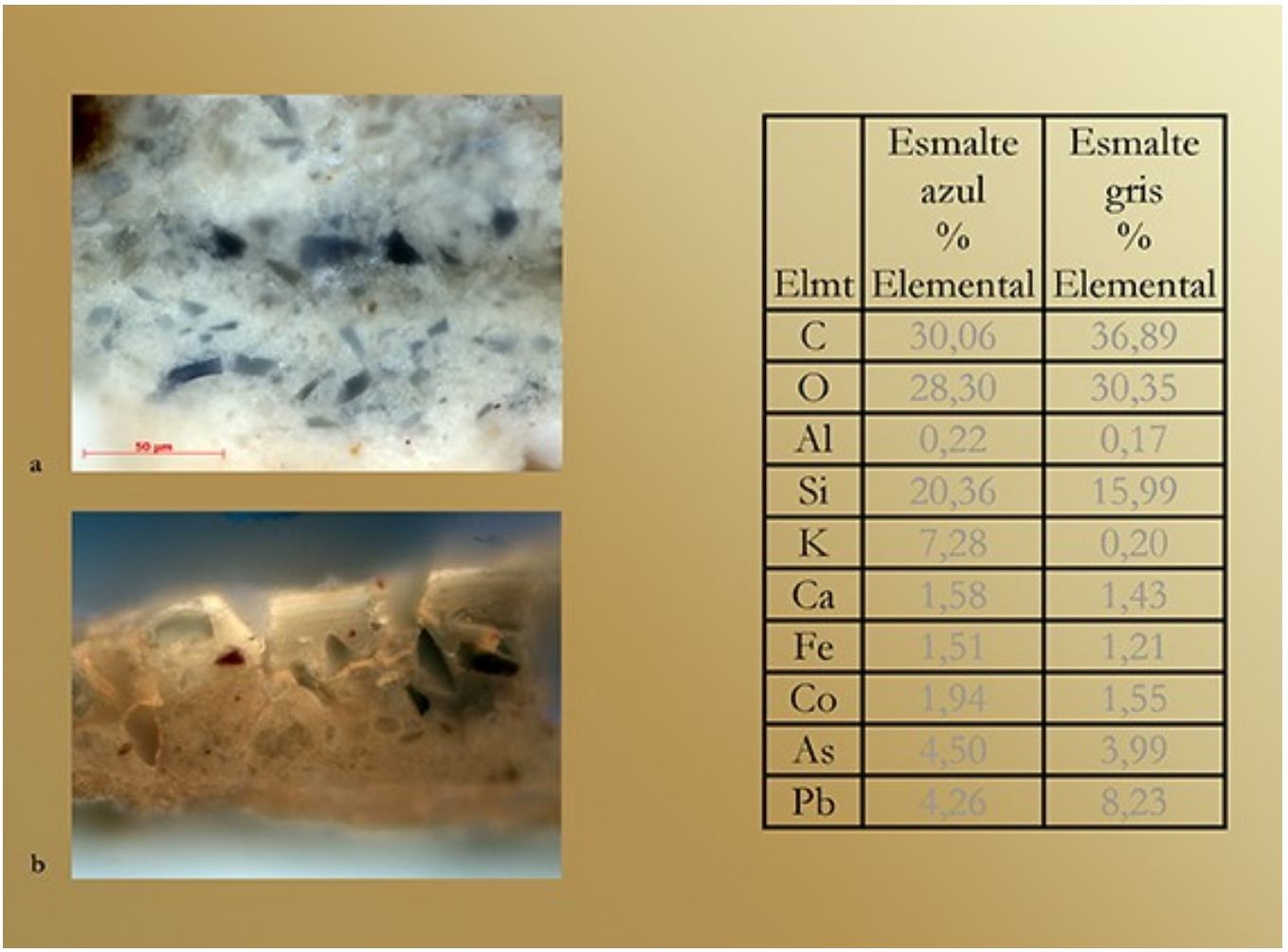

Figura 6. a) Caracterización elemental del esmalte mediante SEM-EDX. Sección transversal del esmalte en la Virgen del Perdón donde se aprecian partículas decoloradas y sin alteración. El análisis comparativo por microsonda EDX de estas partículas muestra la disminución del contenido de potasio y silicio del esmalte degradado. b) En la probeta de la serie No. 3 sometida a $190{ }^{\circ} \mathrm{C}$ se confirmó la decoloración del esmalte.

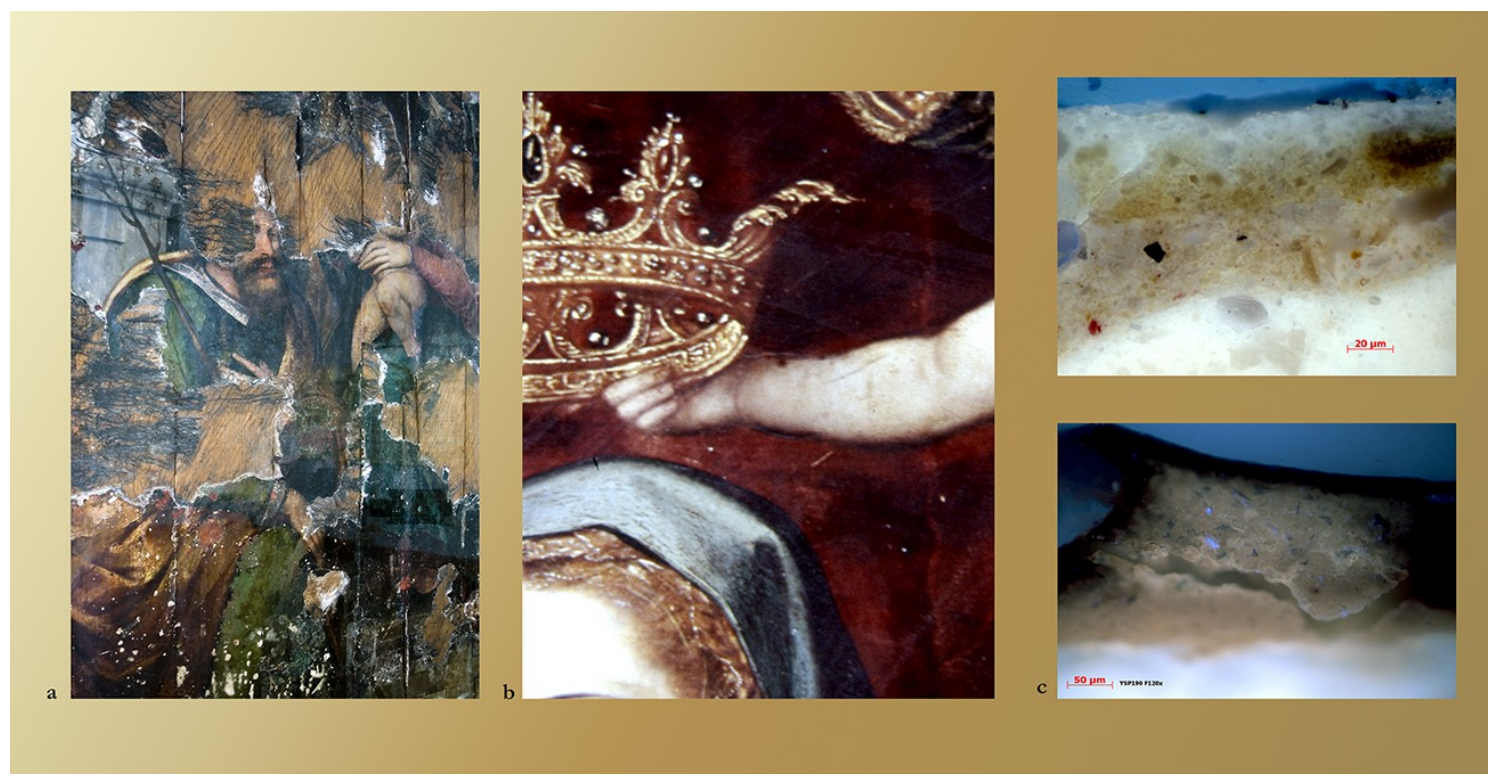

Figura 7. a) Fragmentos conservados en la parte inferior de la Virgen del Perdón. b) Oro a pincel en un detalle de la fotografía de 1965. C) Alteración tonal del aglutinante como efecto del calor y contracción de la película pictórica. Microfotografía de secciones transversales comparativas, arriba, la obra original y abajo, probeta serie No. 3. 
Entre las alteraciones que sufrió la pintura con el incendio se ubica la pérdida de las capas superficiales de pintura. Se detectó que entre los toques finales y detalles que Simón Pereyns aplicó en su obra había pinceladas de oro en emulsión utilizadas para resaltar los mantos de las telas de seda o los elementos iconográficos más destacados en la composición: la corona, las palmas y anillos dorados de los ángeles. Parece que incluso las aureolas de los santos y el resplandor alrededor de la cabeza del niño Jesús, habían sido aplicados con oro. El uso de una emulsión de oro y aceite era bien conocida en la época y constituía un recurso que enfatizaba la dignidad iconográfica de los personajes o atributos simbólicos. De la misma manera, las capas ricas en aglutinante óleo o resina que conforman las veladuras fueron muy alteradas por la temperatura. Las veladuras de laca roja, laca amarilla y un pigmento verde de cobre, se transformaron hacia un color pardo oscuro [figura 7].

\section{Conclusiones}

La Virgen del Perdón es una tabla cuya técnica de manufactura fue cuidadosamente seleccionada por su artífice y resulta distinta de otras obras de la época. Es una pieza temprana en la producción artística de pintura sobre tabla en la Nueva España. Las soluciones técnicas de esta obra son innovadoras para el contexto novohispano. Se ha observado un método de trabajo complejo para la preparación de los aparejos lo que indica el alto nivel de especialización que tenía el taller de Simón Pereyns. Asimismo, se distingue por tener una compleja aplicación de capas pictóricas cuyo objetivo era permitir la vibración del color subyacente a través de las pinceladas en superficie.

En su proceso de ejecución, desde el armado del panel se denota una preocupación por la estabilidad de la pieza. El artista buscó asegurar que los materiales locales fueran aptos para una pieza de gran envergadura y dimensiones. El maestro dirigió los trabajos en su taller y decidió usar dos tipos de madera en el soporte, reforzarlo con tendones de animales preparados in situ y aplicar los estratos preparatorios tras un largo tiempo de secado de la estructura del panel. El espesor de la preparación es excepcionalmente grueso en esta pieza, como se midió por medio de MO y MEB. Resulta interesante la comparación de la Virgen del Perdón con las grandes tablas de Martín Gómez el Viejo, la Presentación en el templo, San Mateo y San Loren₹o - siglo XVI, actualmente en el Museo diocesano de Cuenca-, donde se aprecia una preparación gruesa con refuerzo de fibras. (Santos 2005: 508) Quizá la dimensión de la tabla condicionaba su preparación. Simón Pereyns no lo sabría pero la característica tecnológica del panel y la cuidadosa aplicación de los estratos preparatorios serían responsables de la conservación de la pieza tras el incendio.

Como lo han demostrado estudios de pintura sobre tabla en Europa, el estudio de las bases de preparación aplicadas por los artistas del siglo XVI en diversas regiones ha permitido establecer comparaciones que explican la difusión de maneras de pintar asociadas con escuelas y regiones formativas de los talleres. Para el caso novohispano un análisis comparativo de la materialidad de las tablas del siglo XVI y XVII, podría proporcionar nuevas interpretaciones sobre la relación entre los artistas y la formación de escuelas de pintura.

Al estudiar los efectos del fuego y el incremento de temperatura en los materiales de la Virgen del Perdón, se reveló que los estratos pictóricos se separaron del soporte de madera por la contracción de los tendones de origen animal. La base de preparación sufrió compactación y fractura así como la degradación del aglutinante proteico. Se demostró que el proceso de alteración del yeso mate y grueso por temperatura se debe a un cambio de fase cristalina a partir de $100^{\circ} \mathrm{C}$ y que continuó hasta los $190^{\circ}$ C. Como evidencia de experimentos controlados se expuso la alteración de las estructuras tabulares del yeso, debido a su deshidratación paulatina. 


\section{Agradecimientos}

Este trabajo fue realizado con el apoyo de los Proyectos UNAM PAPIIT IN402007 y Proyecto ININ TM-002. Agradecemos a Leticia Carapia por su apoyo técnico en MEB y DRX.

\section{Notas}

[1] La mañana del 18 de enero los diarios mexicanos presentaron en primera plana la noticia del incendio en la Catedral metropolitana. Eduardo Téllez Vargas, "El altar del perdón, el coro y valiosas pinturas, destruidos" en El Universal. El gran diario de México, año LI, tomo CCVI, Número 18156, México DF, miércoles 18 de enero de 1967, primera plana.

[2] La Virgen del Perdón se resguarda en el Centro Nacional de Conservación y Registro del Patrimonio Artístico Mueble, del Instituto Nacional de Bellas Artes. Agradecemos a la directora Lucia Garcia Noriega por darnos todas las facilidades para realizar el estudio in situ.

[3] Los miembros del equipo de investigación que han desarrollado una metodología de estudio para la pintura del siglo XVI y que participaron en diferentes etapas o procesos de análisis de la Virgen del Perdón son: Elsa Arroyo, Tatiana Falcón, Eumelia Hernández, Sandra Zetina y Víctor Santos del LDOA-IIE-UNAM; Kilian Laclaventine y José Luis Ruvalcaba Sil, Instituto de Física, UNAM; Pablo Amador y Pedro Ángeles del Instituto de investigaciones Estéticas, UNAM; Alejandra Quintanar-Isaías, Departamento de Biología, UAM-Iztapalapa y Manuel Espinosa Pesqueira del Instituto Nacional de Investigaciones Nucleares.

[4] La identificación se realizó comparando las muestras tomadas del tablero con muestras de la colección de maderas de la UAM-Iztapalapa.

[5] El documento fue dado a conocer por Guillermo Tovar y de Teresa y dice: "Se ha de dar toda la dicha obra una mano de siscola y luego se ha de plastecer y de plastecido se ha de raer el dicho plate y enlienzar con lienzo nuevo todas las juntas y más lo que conviene a el provecho de la obra y por las espaldas de las dichas juntas si lo hubiere menester se ha de encibar", ver: (Tovar 1982: 220221). Por otra parte Rocío Bruquetas con información obtenida en documentos españoles ha propuesto que quizá los términos de ennervado y encañamado podrían significar lo mismo, posiblemente debido a la carencia de análisis de identificación de fibras, ya que a simple vista es muy difícil determinar la naturaleza del enfibrado. (Bruquetas 2002: 222).

[6] El texto de Pacheco señala: "Las tablas en que se suele pintar al olio, de borne o cedro, después de ennervadas o encañamadas por detrás las juntas, se les da una giscola de guantes con sus ajos, no muy fuerte y templado su yeso grueso vivo y cernido, se le dan tres o cuatro manos, aguardando a que seque cada una y plasteciendo los hoyos, se templa el [yeso] mate, no muy fuerte, con que se le dan otras cinco o seis manos...”. (Pacheco 2001: 480-481).

[7] Para la preparación del gesso grosso señala: “[...] toma yeso grueso es decir, de Volterra, que esta purificado y tamizado como harina, llena con él una pequeña escudilla, viértelo sobre una piedra de pórfido y con tu mano muélelo bien con ésta cola [...]”; para el gesso sottile dice: "[...] se trata del mismo yeso salvo que se purifica durante un mes teniéndolo en remojo en una tina [...] luego se tira el agua y al yeso se le da forma de pan y se le deja secar [...] toma ese yeso sutil ponlo un pan por vez en una jofaina de agua clara y déjalo absorber el agua que necesite luego paulatinamente ponlo sobre la piedra de pórfido y sin agregarle más agua muélelo con toda perfección. Después sin ensuciarlo, ponlo sobre in retazo de paño de lino fuerte en cantidad suficiente para obtener un pan [...] toma el pan de dicho yeso y con un cuchillo córtalo como si cortaras queso y ponlo en dicha olla viértele luego cola y con la mano ve deshaciendo el yeso [...]”. (Cennini 1947: CXVI y CXVII)

[8] Las placas fotográficas de formato $5 \times 7$ fueron tomadas por Félix Leonelli para ilustrar el libro de Manuel Toussaint, titulado: Pintura Colonial en México, que se publicó por la Universidad Nacional Autónoma de México en 1965. Estas fotografías se encuentran en el Archivo Fotográfico del 
Instituto de Investigaciones Estéticas de la UNAM. Agradecemos esta información a Cecilia Gutiérrez Arriola.

[9] La paleta utilizada por Pereyns en este cuadro se conforma de los siguientes pigmentos: azurita, esmalte, verde resinato de cobre, laca orgánica roja y amarilla -no identificados-, bermellón, rojo y amarillo de plomo, ocre, rojo y tierra compuestos de óxido de hierro, blanco de plomo, amarillo de plomo estaño del tipo II, oropimente, negro de humo y de carbón y polvo de oro aplicado en emulsión. (Arroyo 2008: 48)

[10] Se usó un horno de temperatura constante con control digital controlado por microprocesador, de convección natural marca Precision Scientific modelo 18EG Gravity Convection Oven. Su rango de temperatura va desde ambiente mas 5 grados hasta $190^{\circ} \mathrm{C}$.

[11] El análisis de DRX fue realizado sobre muestras de yeso mate y grueso en polvo, sin haberse mezclado con cola animal preparada.

[12] Se usó amarillo de plomo estaño por la dificultad de preparar en laboratorio el amarillo de plomo o litargirio dada su toxicidad.

[13] Se tomaron fragmentos de alrededor de $0.5 \mathrm{~mm} 3$ de la probeta, se incluyeron en resina poliéster marca Serifix, Struers, en sentido transversal a su superficie, y se pulieron con lijas desde 800 GRIT y paños hasta 4000 GRIT de la misma marca. Esta preparación permite el análisis bajo microscopio óptico, se utilizó el Axiotec, de la marca Zeiss, que cuenta con una cámara digital Axiocam MRC, las imágenes se procesaron con el programa AxioVision Rel. 4.6.

[14] Temperatura máxima alcanzada al reproducir experimentalmente en laboratorio un incendio forestal, (Zárate 2004: 79)

[15] También se hizo tratamiento térmico de yeso mate a $210^{\circ} \mathrm{C}$, encontrándose la presencia de la fase cristalina anhidrita en $95 \%$ y restos de basanita en $5 \%$ en peso.

[16] Entre 1584 y 1585 ejecutaron el retablo mayor de la vieja Catedral de México. (Toussaint 1965: 5163); en 1581 realizaron las puertas del retablo de Teposcolula, (Romero 1978: 13); en 1584 firmaron el contrato del retablo mayor de Huejotzingo, (Berlin 1958: 63-73).

[17] La degradación del esmalte ha sido estudiada en pinturas de Pedro de Campaña (La Conversión de Magdalena, atribuido,1562), Joachim Bauckelaer (Los cuatro elementos: agua, 1570) y Brueguel (La Adoración de los reyes, 1564), por citar algunos. (Spring 2005: 56-70).

\section{Bibliografía}

AMADOR, P., ÁNGELES, P., ARROYO, E., et al. (2008). "Y hablaron de pintores famosos de Italia. Estudio interdisciplinario de una nueva pintura novohispana", en Anales del Instituto de Investigaciones Estéticas, 2008, vol. XXX, 92: 49-83, www.analesiie.unam.mx/pdf/92 49-83.pdf [consulta: 4/6/2008]

ARROYO, E. (2008). "Biografía de una ruina prematura: la Virgen del Perdón de Simón Pereyns", en Goya. Revista de Arte, 327, Julio 2009.

ARROYO, E. (2008). "Del perdón al carbón. Biografía cultural de una ruina prematura”. Tesis de Maestría en Historia del Arte, México: Facultad de Filosofía y Letras e Instituto de Investigaciones Estéticas, UNAM. Versión electrónica: http://www.dgbiblio.unam.mx. [ consulta: 10/12/2008]

BERLIN, H. (1958) "The High Altar of Huejotzingo", The Americas, Washington, v. XV, 1: 63-73.

BRUQUETAS GALÁN, R. (2002).Técnicas y materiales de la pintura española en los siglos de oro. Madrid: Fundación de Apoyo a la Historia del Arte Hispánico. 
CENNINI, C. (1947) El Libro del Arte. Buenos Aires: Argos.

GETTENS, R.J. y MROSE, M.E. (1954). "Calcium sulfate minerals in the grounds of italian paintings", Studies in Conservation, v. 1, 4: 174-189.

MARTIN, E., SONODA, N., Duval, A.R. (1992). "Contribution a l'etude des preparations blanches des tableaux italiens sur bois", Studies in Conservation, v. 37, 2: 82-92.

PACHECO, F. (2001) El Arte de la pintura. Madrid: Cátedra.

RAMACHANDRAN, G.N. (1967). "Structure of collagen at the molecular level". En Treatise on collagen, Vol. 1: Chemistry of collagen, Ramachandran, G.N. (ed.), Vol. 1. London: Academic Press, 103-183.

ROMERO FRIZZI, Ma A. (1978). Más ha de tener este retablo.... México: INAH.

SANTOS GÓMEZ.S., SAN ANDRÉS, M., RODRÍGUEZ, A. (2005). "Las preparaciones de yeso en la pintura sobre tabla de la escuela española". Tesis de doctorado, Madrid: Universidad Complutense de Madrid. Versión digital: http://eprints.ucm.es/tesis/bba/ucm-t28904.pdf [consulta: 15/6/2009]

SANTOS G. S. (2008). "Reconstruction of document preparation methods for gesso grosso and gesso sottile in Spanish School panel paintings". En Art Technology. Sources and Methods. Proceedings of the Second Symposium of the Art Technological Source Research Study Group. Londres: Archetype, 178-181.

SPRING, M., HIGGIT, C., SAUNDERS, D. (2005). "Investigation of Pigment-Medium Interaction Processes in Oil Paint containing Degraded Smalt". National Gallery Technical Bulletin, v. 26: 56-70.

TOUSSAINT, M. (1965). Pintura colonial en México. México: Instituto de Investigaciones Estéticas, Universidad Nacional Autónoma de México.

TOVAR Y DE TERESA, G. (1982). Renacimiento en México. Artistas y retablos. México: SAHOP.

VON HIPPEL, P. H. (1967). "Structure and stabilization of the collagen molecule in solution". En Treatise on collagen, Vol. 1: Chemistry of collagen, Ramachandran, G.N. (ed.). Londres: Academic Press, 253-338.

WOESSNER Jr., J. F. (1961). "The determination of hydroxyproline in tissue and protein samples containing small proportions of this amino acid", Archives Biochemistry Biophysics, 93: 440-447.

ZÁRATE LÓPEZ, L. (2004) "Estudio de las características físicas y geométricas de la llama en los incendios forestales". Tesis doctoral, Universidad de Cataluña. Versión electrónica: http://www.tdx.cat/TDX0503104-095443 [consulta: 5/7/2008]

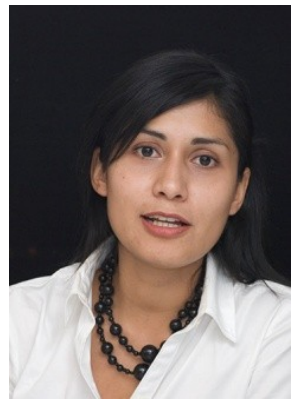

\section{E. M. Arroyo Lemus}

Laboratorio de Diagnóstico de Obras de Arte, Instituto de Investigaciones Estéticas, Universidad Nacional Autónoma de México, Circuito Mario de la Cueva s/n, Zona Cultural, Ciudad Universitaria, México, D. F., 04510, Tel: (5255) 56227320, Fax: (55) 5665-4740.Email: elsa2001@gmail.com

Elsa Minerva Arroyo Lemus Maestra en Historia del Arte por la Facultad de Filosofía y Letras de la UNAM, licenciada en Historia por la misma facultad y licenciada en Restauración de Bienes Muebles por la ENCRM. Se ha especializado en el estudio de las técnicas y materiales de la pintura novohispana. 


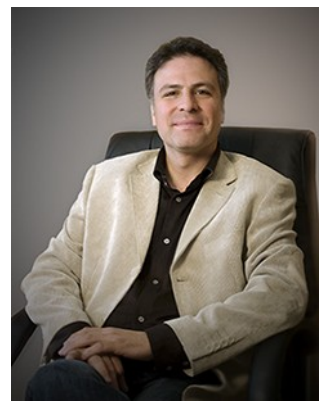

\section{E. Espinosa Pesqueira}

Departamento de Tecnología de Materiales, Instituto Nacional de Investigaciones Nucleares

Carretera México-Toluca s/n, La Marquesa, Ocoyoacac, 52750, México, Tel: 5255-53297200 ext. 2847. Email: manuel.espinosa@inin.gob.mx

Manuel E. Espinosa Pesqueira Es doctor en Ciencia de Materiales por la Universidad Autónoma del Estado de México, especialista en microscopia electrónica de alta resolución, difracción de rayos X y síntesis de nanocompuestos. Responsable de los laboratorios de microscopia electrónica del ININ

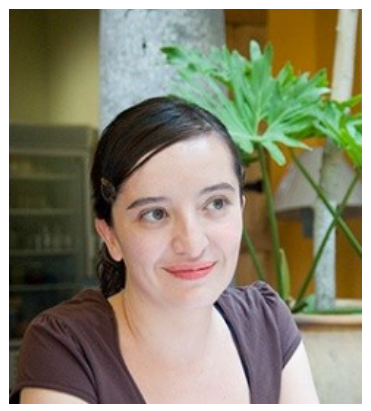

\section{S. Zetina Ocaña}

Laboratorio de Diagnóstico de Obras de Arte. Email: sandra.zetina@gmail.com

Sandra Zetina Ocaña Licenciada en restauración de bienes muebles por la ENCRM, especialista en estudio de técnica pictórica en obras de arte mexicano.

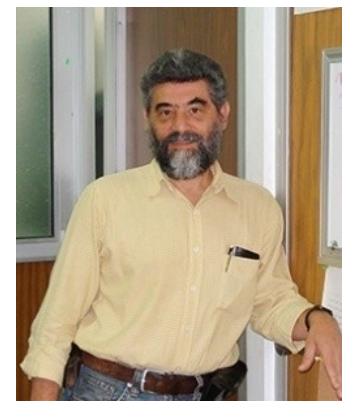

\section{A. Torre Blanco}

Departamento de Biología Celular, Facultad de Ciencias, UNAM, Circuito Exterior s/n, 04510. Email: atb@unam.mx

Alfonso Torre Blanco Doctor en Bioquímica por la Facultad de Química de la UNAM. Profesor titular en la Facultad de Ciencias de la UNAM. Especialista en Antropología Molecular. 


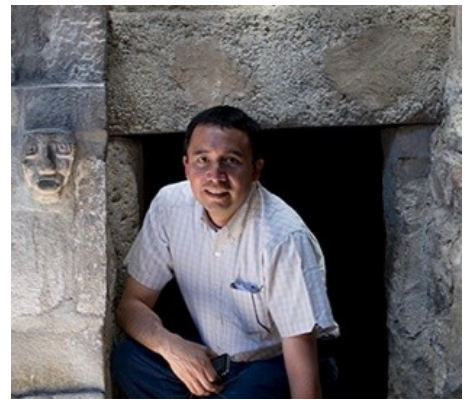

\section{J.L. Ruvalcaba}

Instituto de Física, Universidad Nacional Autónoma de México, 04510, Apdo. Postal 20-364, México D. F. 01000, Tel: + 5255 56225162 / 56225005. Email: sil@fisica.unam.mx

José Luis Ruvalcaba. Doctor en Ciencias (Física) por la Faculté des Sciencies, Facultés Universitaires NotreDame de la Paix, Namur, Bélgica. Su área de especialidad: análisis de materiales mediante haces de iones; caracterización no destructiva de material arqueológico, histórico y artístico; arqueometría.

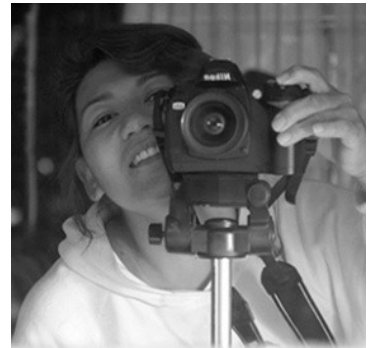

euihernandez@gmail.com

\section{E. Hernández Vázquez}

Laboratorio de Diagnóstico de Obras de Arte. Email:

\section{Eumelia Hernández Vázquez}

Maestra en Historia del Arte por la Facultad de Filosofía y Letras de la UNAM. Es especialista en fotografía científica de obras de arte.

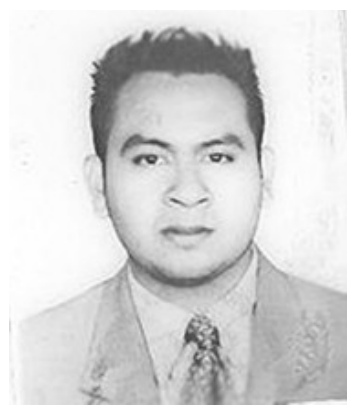

\section{E. Hernández Vázquez}

Laboratorio de Diagnóstico de Obras de Arte. Email: lvlvics@gmail.com Ingeniero

V. Santos Vázquez. Químico egresado de la Escuela Superior de Ingeniería Química e Industrias Extractivas, del Instituto Politécnico Nacional. Se especializa en secciones transversales para microscopia.

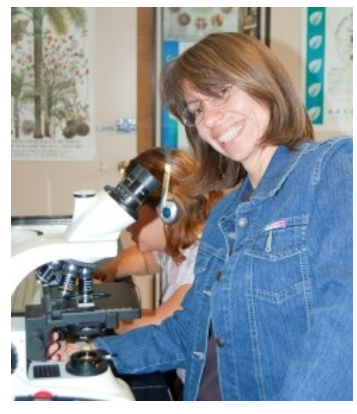

\section{A. Quintanar-Isaías}

Laboratorio de Anatomía y Tecnología de la Madera, Departamento de Biología. Universidad Autónoma Metropolitana. Tel: + (55) 58-04-4699.

Email: aqi@xanum.uam.mx.

Alejandra Quintanar-Isaías. M. en C. Especialista en anatomía funcional de órganos vegetales e identificación de maderas arqueológicas, novohispanas y modernas. 